\title{
Admission on Gulf War vaccines spurs debate on medical records
}

[PARIS] Pressure in the United Kingdom for an overhaul of military medical research was reinforced last week by an admission from the UK Ministry of Defence (MOD) that it had failed to heed warnings at the start of the Gulf War about the possible side-effects of a vaccine combination administered to British troops.

A report presented to the House of Commons by John Reid, the armed forces minister, confirms that a pertussis (whooping cough) vaccine was given to troops as an adjuvant for an anthrax vaccine, so that the latter took effect after seven instead of 32 weeks.

Use of the pertussis vaccine in this way was highly experimental, relying on preliminary results from MOD-sponsored research at the Centre for Applied Microbiology Research (CAMR) at Porton Down, but was done to get troops out to the Gulf quickly.

But the report reveals that the National Institute for Biological Standards and Control (NIBSC) had warned the MOD, in a fax dated 21 December 1990, that in animal studies this combination caused "severe loss of condition and weight". Although the MOD recorded receipt of the fax, no-one there could recall "or admitted to recalling the fax", said Reid.

The revelations have also lent weight to suspicion that vaccinations might account for some of the purported symptoms of Gulf War syndrome. A recent paper, by Graham Rook and A. Zumla from University College London, suggests that multiple vaccinations may cause a large change in the immune response that could result in similar symptoms to those observed in Gulf War veterans (see The Lancet349, 1831;1997).

Circumstantial evidence pointing to vaccines as a cause for the syndrome also comes from the fact that no symptoms have been reported in French forces, who were not given

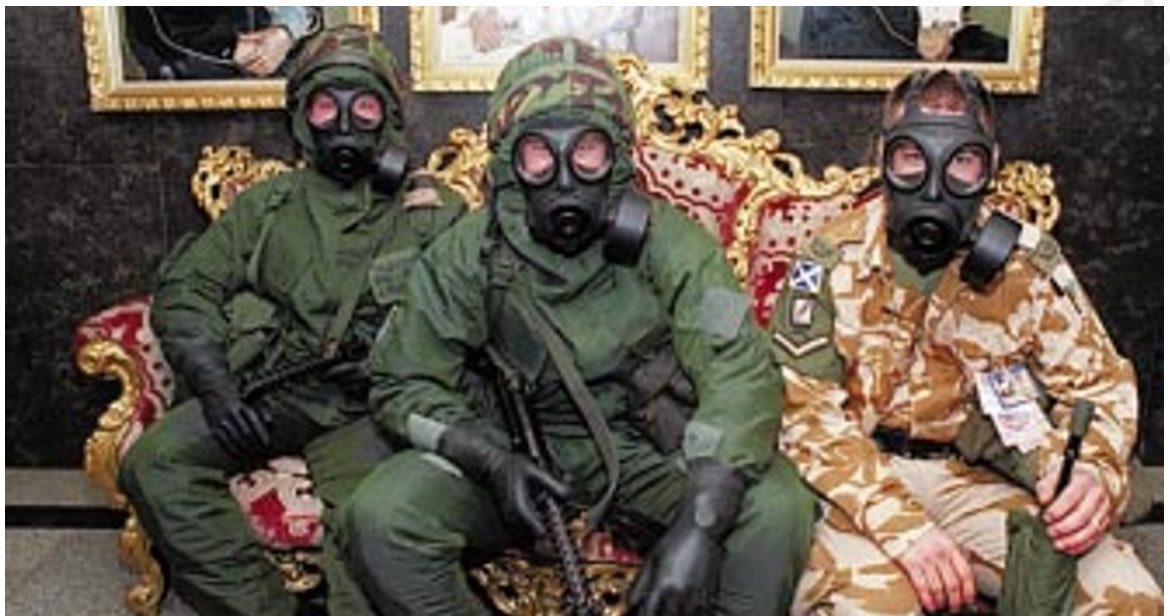

Ready for action: but did haste in getting troops to the Gulf mean that short-cuts were taken?

the vaccines used by British and US troops.

If this difference is confirmed, it would be a "crucial epidemiological point", says Simon Wessely, a researcher at King's College in London who is leading a study on Gulf War syndrome. But he adds: "I'm only prepared to accept this when there is evidence that the French have looked for [symptoms]; they haven't systematically looked yet."

Whether or not the vaccine combination did in fact harm soldiers, the British admission, coming seven years after the incident, has raised new questions about the government's handling of the Gulf War syndrome controversy. And further queries arise from last week's revelations that a former defence minister gave incorrect information to Parliament on the extent of the use of organophosphate pesticides during the war.

Most observers conclude that the MOD could have done more to test the prophylaxis given to troops. They point in particular, to the fact that the NIBSC's action in checking the safety of using pertussis as an adjuvant

\section{Ariane-5 saves Europe's place in space}

[PARIS] Europe's Ariane-5 launcher, which exploded on its maiden flight last year, is back on track after last week's successful launch from Kourou in French Guiana. The launcher, which cost US\$7 billion to develop, is Europe's main space project and its ticket to maintaining its autonomy in space and continuing its dominance of the commercial launch market.

A repeat of the first failure, which cost the European Space Agency \$350 million, would have plunged Europe's cash-strapped space programme into crisis (see page 8 ).
Ariane 5 was originally designed to carry Hermès, a planned European space shuttle that has since been abandoned. Somewhat poignantly, France last week decided to withdraw from the last relic of its Hermès activities, a joint US-European programme to build a crew rescue vehicle for the international space station. The decision reflects the aversion of Claude Allègre, the new space minister, to manned space flight, as well as the end of the country's ambitions in this area. owed more to chance than to MOD research planning. The MOD asked the NIBSC only to verify the safety of the pertussis vaccine which was licensed in France but not in the United Kingdom - without revealing that the vaccine was to be used as an adjuvant. But the NIBSC "deduced" that this was the purpose and "therefore decided that a check for interactions might be helpful", according to the report.

"MOD suffers from an excessive culture of secrecy; they don't deal well with outside researchers," says one academic UK researcher who has worked with the MOD on Gulf War syndrome. He describes the ministry as "hideously complicated", adding that while he has had "excellent help" from parts of it, others have given him none.

The government comes in for similar criticism over its announcement last week

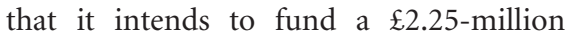
research programme into the effects of the combination of vaccines and anti-nerve gas treatments that were given to troops; many describe this action as belated. But other observers warn against excessive hindsight, and sympathize with the dilemma created by the need to protect troops when licensed products may not be available.

For example, Jack Woodall, director of the arbovirus laboratory at the New York State Department of Health in Albany, and an expert on biological weapons, describes the MOD's admitted failure to keep proper medical records as having resulted in a "missed opportunity to to do a proper scientific study to see who responded to vaccines and combinations".

But Colonel Wilbur Milhous, director of experimental therapeutics at the Walter Reed Army Institute of Research in Washing- 
ton DC, argues that carrying out such studies under deployment conditions is often unrealistic. "In Bosnia, conditions were horrendous. One guy was given a jeep and a technician and told to go out and immunize thousands of people.... just getting the vaccines delivered was a major accomplishment, much less keeping records of who got what."

Similarly, one former CAMR official claims that a ceiling imposed for political purposes on the number of UK servicemen that could be sent to the Gulf led to economies in medical research staff. "It would have been nice to have people collecting data [on the effects of prophylaxis], but it was more important to have tank forces than clever scientists. I remember there were tight constraints."

The controversy about Gulf War syndrome has sparked renewed attention in the United States to protocols associated with experimental prophylaxis and therapeutics under battlefield conditions; review panels are being set up by the Food and Drug Administration and the Department of Defense to consider the issue.

But, according to Wessely, even if practical constraints to substantially improving the conduct of research in deployment settings are accepted, much could still be done to improve post-conflict surveillance, "There is no excuse for the sluggish response of those in authority to sick servicemen coming back from war," he says.

Although military service will always create its own health problems, the United Kingdom has failed to establish "a routine system for data collection, epidemiological surveillance, and follow-up", he says. If such a system had been in place at the time of the Gulf War, he adds, it would have been much easier to look for patterns and conclude whether there was a problem or not.

One recommendation his group's study is likely to make is that the health of veterans should automatically be monitored so that unusual outbreaks of cancer, reproductive defects or deaths can be detected. At present, it is impossible to tell whether servicemen suffer from higher levels of cancer, for example, says Wessely.

Veterans need to be treated as a special group for research purposes, with particular health needs, he says. "Regardless of whether Gulf War syndrome exists or not, many veterans are bitter and disillusioned at the feeling there has been official disregard for their health."

On a wider level, the short-cut taken by the MOD in using pertussis vaccine as an experimental adjuvant for an anthrax vaccine raises the question of why the ministry had not carried out comprehensive research into developing a fast-acting anthrax vaccine sooner. A former official from Porton Down says that the West was unprepared for the threat of an enemy striking rapidly with biological and chemical weapons. DeclanButler

\section{Critics claim US inquiry was 'irreparably flawed'}

[WASHINGTON] The US government came under renewed heavy criticism last week for its investigations and handling of the elusive collection of symptoms known as 'Gulf War illnesses'. Two reports, one adopted by a congressional committee and one still in draft form, have highlighted research into chemicals exposure during the war.

The House of

Representatives Committee on Government Reform and Oversight adopted unanimously a report that assails the Departments of Defense (DOD) and Veterans Affairs (VA) for the weakness of their efforts to establish the cause or causes of Gulf War illnesses. This failing of research, the report says, as well as lapses by the Central Intelligence Agency (CIA) and the Food and Drug Administration (FDA), amount to a government effort that the congressional committee called "irreparably flawed".

In particular, says the 140page report, the DOD and VA resisted and then

mishandled investigations into chemicals exposures as a potential source of the various symptoms experienced by some 100,000 Gulf War veterans. The departments' behaviour, it says, has been "plagued by arrogant incuriosity and a pervasive myopia that sees a lack of evidence as proof".

Among the report's recommendations are that the DOD and VA should lose their authority over further research on Gulf War illnesses to another agency able to develop a research agenda "more objectively".

Equally harsh criticism is contained in another report still officially private - handed on 31 October to President Bill Clinton, who is expected to release and react to it within two weeks. That report, by the Presidential Advisory Committee on Gulf War Veterans' IIInesses, praises the DOD for improving its research, but says the Pentagon "failed to pursue, acknowledge or even account for" chemicals exposures said to have been detected by US Marines who crossed an Iraqi minefield when entering Kuwait in February 1991.

A draft of this presidential report was obtained by the New York Times, which printed excerpts last week. These called the DOD's failure to investigate the minefield incident fully "highly damaging to DOD's credibility". The news account quotes the report as stating that "the comittee perceives that public mistrust about the Government's handling of gulf war veterans' illnesses has not only endured, it has expanded".

The VA and DOD declined to respond officially to the presidential report until it is made public. But Captain Tom Gilroy, a DOD spokesman, calls the February 1991 minefield incident "old news", and points out that since July, the DOD has had posted on its website a full account of the incident, as well as a related chapter from a top-secret report compiled for DOD by the Mitre Corporation of Bedford, Massachusetts. (The website address is

http://mww.gulflink.osd.mil.)

Joyce Lashof, chair of the Presidential Advisory Committee and a professor emerita of public health at the University of California, Berkeley, also declined to comment on the substance of her committee's report. But she said any exposure suffered by Marines in the February 1991 incident was "very low level, subclinical", and that the committee stands by the position it took in a January 1997 report: "that available scientific evidence does not indicate that longterm health effects occur in humans following low-level exposure to chemical warfare agents".

The congressional report argues otherwise, calling the circumstantial evidence for such a link "overwhelming". But it says proof may be lost forever because of the DOD's and VA's handling of the research. The departments, says the report, prematurely ruled out toxic exposure as a cause of Gulf veterans' symptoms, assuming that unless there was an immediate acute reaction, exposure could not have caused long-term symptoms. As a result, "federal research strategy has been blind to promising hypotheses", the report states.

Citing a 1997 report by the General Accounting Office, it notes, for instance, that the government funded multiple studies of the role of stress in Gulf War illness, but not until forced by legislation in 1996 did it begin funding studies on the effects of low-level chemicals exposure. Three such studies had previously been denied funds.

Responding to the congressional report, Gilroy of DOD says that "in the last year we have done a lot of work and I don't know if any of it is reflected in [the House report]". The work referred to is that done by the DOD's Office of the Special Assistant for Gulf War Illnesses, set up in November 1996 to oversee DOD research.

And the VA says the report fails to "recognize the openness and public accountability of the existing research effort". Also, says a VA spokesman, Terry

Jemison, VA research undergoes vetting to protect it from political influence.

Despite all these protestations, the lead author of the congressional report, Congressman Christopher Shays (Republican, Connecticut), has promised to draft legislation early in 1998 removing investigative powers from the DOD and VA. 